\title{
Time-integrated thermal bleaching thresholds of reefs and their variation on the Great Barrier Reef
}

\author{
Ray Berkelmans* \\ Great Barrier Reef Marine Park Authority, PO Box 1379, Townsville, Queensland 4810, Australia
}

\begin{abstract}
Knowledge of the critical levels for key environmental variables that are likely to cause bleaching in reef corals is of fundamental importance in conducting risk assessments of potential climate-change effects on coral reefs. Such knowledge can also be used to provide early warning of mass bleaching events. A number of factors have contributed to the difficulty in determining critical levels for coral bleaching. These factors include the fact that multiple stressors may be involved in bleaching, the duration of stress required to elicit a bleaching response varies with temperature, and bleaching triggers are known to be variable in space, time and by species. In this study, I identify sea surface temperature (SST) as the most important parameter for predicting coral bleaching from 4 possible environmental variables collected over 10 to $12 \mathrm{yr}$ from weather stations at 2 locations on the Great Barrier Reef (GBR): temperature, wind speed, solar radiation and barometric pressure. Predicted bleaching-response curves are constructed from high-resolution in situ temperature records and historical observations of coral bleaching for 13 locations. These curves approximate reef-wide stress-response thresholds for bleaching of thermally sensitive (and often dominant) coral species. Distinct spatial trends exist in the thermal sensitivity of coral populations that correspond with position across the shelf and latitude in the case of mid- and outer-shelf reefs. This suggests that considerable thermal adaptation has taken place over small $(10 \mathrm{~s}$ of $\mathrm{km})$ and large (100s to $1000 \mathrm{~s} \mathrm{of} \mathrm{km}) \mathrm{spa}-$ tial scales. Bleaching curves for inshore reefs do not correspond with latitude and are more variable, reflecting greater local-scale variability in temperature regimes.
\end{abstract}

KEY WORDS: Temperature $\cdot$ Coral $\cdot$ Bleaching $\cdot$ Threshold $\cdot$ Climate change

\section{INTRODUCTION}

Concern about the possible link between climate change and major impacts on the world's coral reefs as a result of coral bleaching (e.g. Glynn 1993) has stimulated research into modeling potential future scenarios of sea temperatures in reef regions (e.g. Hoegh-Guldberg 1999). Such models provide a basis for undertaking sensitivity and risk analyses aimed at identifying and quantifying threats to coral reefs from climate change. Risk assessments thus provide a scientific basis for policy and management responses at local, regional and global scales. To assess risks to coral

\footnotetext{
*Present address: Australian Institute of Marine Science, PMB 3 Townsville, Queensland 4810, Australia.

E-mail: r.berkelmans@aims.gov.au
}

reefs, impact thresholds for a variety of climate variables must be identified which can be combined with climate model forecasts to estimate the probability of exceeding such thresholds (Pittock 1999). One of the most important environmental criteria defining the existence of coral reefs is temperature (see reviews by, e.g. Stoddart 1969, Achituv \& Dubinsky 1990, Kleypas et al. 1999). However, defining the upper thermal limits of coral reefs in anything but general terms has proved surprisingly difficult. While considerable progress has been made in establishing the experimental upper thermal limits of corals from a variety of species and from a number of areas (e.g. Coles et al. 1976, Markus \& Thorhaug 1981, Berkelmans \& Willis 1999), it is not clear how these experimentally derived upper thermal limits apply in situ, where a number of stress factors may work in concert to alter the effective 
bleaching thresholds (see reviews by Jokiel \& Coles 1990, Glynn 1993, Brown 1997, Hoegh-Guldberg 1999). Low winds and high irradiance, for example, are commonly associated with reef-wide bleaching events (Dennis \& Wicklund 1993, Drollet et al. 1994, McField 1999). Barometric pressure may also be correlated with bleaching because of its regional influence on winds and ocean currents (Lough 2001). Bleaching responses also vary with exposure time, species and location (e.g. Coles et al. 1976, Marcus \& Thorhaug 1981, Glynn et al. 1989). In combination, these factors have made it difficult for temperature thresholds to be used in modeling the effects of climate change on coral reefs. Determining in situ, time-integrated bleaching thresholds and their spatial variation, especially over local and regional scales, is thus essential to advance our knowledge in this area.
Knowledge of realized in situ bleaching thresholds also allows near real-time prediction of bleaching events using automatic weather stations (Hendee et al. 1998). Early warning of local conditions likely to cause coral bleaching could augment regional satellite-based 'hotspot' alerts (Strong et al. 1997) to assist: (1) science, in documenting and researching the phenomenon; (2) public relations, in keeping reef-based commercial operators, politicians and the general public informed; (3) coral reef managers, in ameliorating local-scale human impacts which might exacerbate coral bleaching.

In this study I examine 10 to $12 \mathrm{yr}$ of automatic weather station data to establish the relative importance of sea surface temperature (SST), wind speed, photosynthetically active radiation (PAR) and barometric pressure as predictor variables of coral bleaching on the Great Barrier Reef (GBR) in 1998. I establish best-estimate, time-integrated thermal bleaching thresholds based on 3 to $8 \mathrm{yr}$ of in situ temperature data for 13 locations on the GBR and examine their characteristics and variation with latitude and shelf position.

\section{MATERIALS AND METHODS}

Data from the Australian Institute of Marine Science automatic weather stations at Myrmidon Reef (latitude $18.2^{\circ} \mathrm{S}$, longitude $147.2^{\circ} \mathrm{E}$ ) and Hardy Reef (latitude $19.8^{\circ} \mathrm{S}$, longitude $149.2^{\circ} \mathrm{E}$ ) in the central GBR covering 12 and $10 \mathrm{yr}$ (respectively) were used to determine conditions associated with the major GBR bleaching event of early 1998 (Baird \& Marshall 1998, Berkelmans \& Oliver 1999, Marshall \& Baird 2000; Fig. 1). Weather station sensors, including sea temperature (Omega Interchangable Thermister), wind speed (R. M. Young 5103), PAR (Li-Cor 192SA, 400 to $700 \mathrm{~nm}$ ), and barometric pressure (Vaisala PTB101B), were scanned and averaged every $30 \mathrm{~min}$. I compared average monthly values of these variables for the warmest month during the 1998 bleaching event (February), with weather conditions occurring between January and March of all other years. These months are when bleaching on the GBR has previously occurred (Oliver 1985, Jones et al. 1997). PAR was averaged between 10:00 and 15:00 h each day to capture the mean
Fig. 1. Map of the Great Barrier Reef showing the location of reefs for which bleaching curves were estimated and the location of automatic weather stations at Myrmidon and Hardy Reef (italics) 
maximum daily irradiance as an indicative measure of potential light stress to corals.

Data-logger SST data from 13 locations on the GBR were examined for which concurrent information was also available on the intensity of bleaching during 1998 (Table 1, and Berkelmans \& Oliver 1999). These locations comprised 6 inshore reefs (Wallace Islet, Daintree Coast, Orpheus Island, Magnetic Island, Daydream Island, Halfway Island), 3 mid-shelf reefs (Low Isles, Kelso Reef, Davies Reef) and 4 outer-shelf reefs (Norman Reef, Myrmidon Reef, Chicken Reef, Heron Island: Fig. 1). Temperatures at each location were continuously monitored over periods of 3 to $9 \mathrm{yr}$. Loggers were calibrated against a certified reference thermometer after every download (6 to $12 \mathrm{mo}$ ). Daily mean SSTs ( $n=48$ records) were calculated for the reef flat (lowest astronomical tide) and slope (5 to $9 \mathrm{~m}$ ) at all sites. At locations where multiple loggers were deployed within $15 \mathrm{~km}$ of each other (Daintree coast, Orpheus Island, Magnetic Island, Halfway Island), data were also spatially averaged. Temperatures used in this analysis, therefore, broadly represent the general area at each location and the depth-range of the majority of corals. For each location, the cumulative time (in days) at each temperature was calculated for the period December to March each year, which includes the austral summer. The resultant time-temperature curves, therefore, are the tail end of cumulative frequency distributions of temperatures for each year. For each location, a polynomial bleaching curve was then interpolated between the warmest non-bleaching year and the coolest bleaching year. The position of the bleaching curve between these years was estimated by the severity of bleaching as recorded on a 5-point scale, with 1 being the most severe bleaching state and 5 being the least severe bleaching state (Table 1), according to the equation:

$$
b_{\mathrm{c}}=T_{\mathrm{b}}-s / 5\left(T_{\mathrm{b}}-T_{\mathrm{n}}\right), \text { for } T_{\mathrm{b}}>T_{\mathrm{t}}
$$

where $b_{\mathrm{c}}$ is the predicted bleaching curve, $s$ is the bleaching severity score (integer between 1 and 4 ), $T_{\mathrm{b}}$ is the temperature distribution curve for the coolest bleaching year (if the temperature data include more than 1 bleaching year), $T_{\mathrm{n}}$ is the temperature distribution curve for the warmest non-bleaching year, and $T_{\mathrm{t}}$ is the threshold temperature $\left({ }^{\circ} \mathrm{C}\right)$. The threshold temperature is the highest temperature at which no bleaching is predicted to occur irrespective of exposure time and is taken as the point where the bleaching and non-bleaching temperature curves overlap (i.e. when $T_{\mathrm{n}}>T_{\mathrm{b}}$ ). A bleaching curve, therefore, represents a profile of average daily exposure temperatures and durations at which coral bleaching in thermally sensitive species is predicted to commence. As the resultant curves are based on distribution curves, the number of
Table 1. Location of reefs used to construct bleaching curves and bleaching status as assessed from aerial surveys undertaken using fixed-wing aircraft at an altitude of $\sim 160 \mathrm{~m}$ between 9 March and 10 April 1998. Reefs were classified into 5 categories of bleaching severity: 1 (extreme, >60\% bleached), 2 (very high, 30 to $60 \%$ bleached, 3 (high, 10 to $30 \%$ bleached), 4 (moderate, 1 to $10 \%$ bleached), and 5 (no or low bleaching, $<1 \%$ bleached)

\begin{tabular}{|lccc|}
\hline Reef & $\begin{array}{c}\text { Latitude } \\
\left({ }^{\circ} \mathrm{S}\right)\end{array}$ & $\begin{array}{c}\text { Longitude } \\
\left({ }^{\circ} \mathrm{E}\right)\end{array}$ & $\begin{array}{c}\text { Bleaching } \\
\text { category }\end{array}$ \\
\hline Wallace Islet & 11.4 & 143.0 & 4 \\
Daintree coast & 16.2 & 145.4 & 2 \\
Low Isles & 16.4 & 145.6 & 1 \\
Norman Reef & 16.4 & 146.0 & 4 \\
Myrmidon Reef & 18.3 & 147.4 & 4 \\
Orpheus Island & 18.6 & 146.5 & 1 \\
Kelso Reef & 18.4 & 147.0 & 4 \\
Chicken Reef & 18.7 & 147.7 & 4 \\
Davies Reef & 18.8 & 147.6 & 4 \\
Magnetic Island & 19.2 & 146.8 & 1 \\
Daydream Island & 20.3 & 148.8 & 4 \\
Halfway Island & 23.2 & 151.0 & 1 \\
Heron Island & 23.4 & 151.9 & 4 \\
\hline
\end{tabular}

days exposure do not necessarily represent consecutive days. However, because temperatures from day-today are highly auto-correlated, the periods of warm weather of primary interest in this study generally occurred in 1 or several closely following blocks of time.

Because the bleaching curves are derived from highly auto-correlated data, modeling these curves with traditional statistical routines based on leastsquares regression procedures is technically flawed. The end result is an underestimation of the error around the curve. This would therefore make statistical comparisons of individual curves difficult. However, as I was mainly interested in the predictive capacity of the curves at a particular location (i.e. how much temperature for how long?) and in gross regional trends in bleaching thresholds, I proceeded with modeling the curves. In doing so, I acknowledge that there is variation around each curve, but also show that this variation is likely to be relatively small (see 'Discussion'). Regional trends in the slope and offset of bleaching curves (based on linear models) were employed on the basis that the slope and offsets of curves for each location are independently estimated and thus can be used legitimately in regression models.

The relationship between the bleaching curves and the concept of accumulated thermal stress (Gleeson \& Strong 1995) was investigated by converting bleaching curves to 'degree-days' (exposure days $\times$ temperature in excess of threshold temperature, $T_{\mathrm{t}}$ ) and plotting the resultant values against temperatures in excess of the threshold temperature. 

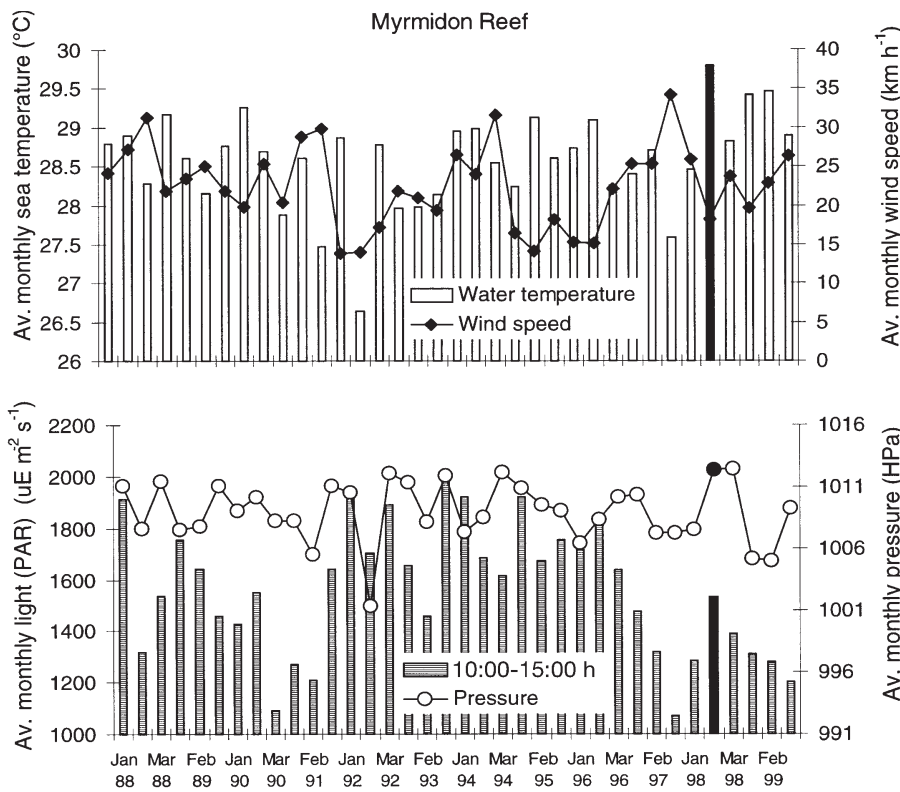

Fig. 2. Average monthly sea temperature, wind speed, daytime solar radiation and barometric pressure for Myrmidon Reef for the months of January, February and March between 1988 and 1999. Widespread coral bleaching was evident at this reef in February 1998 (black bars), but at no other time during this 12 yr period
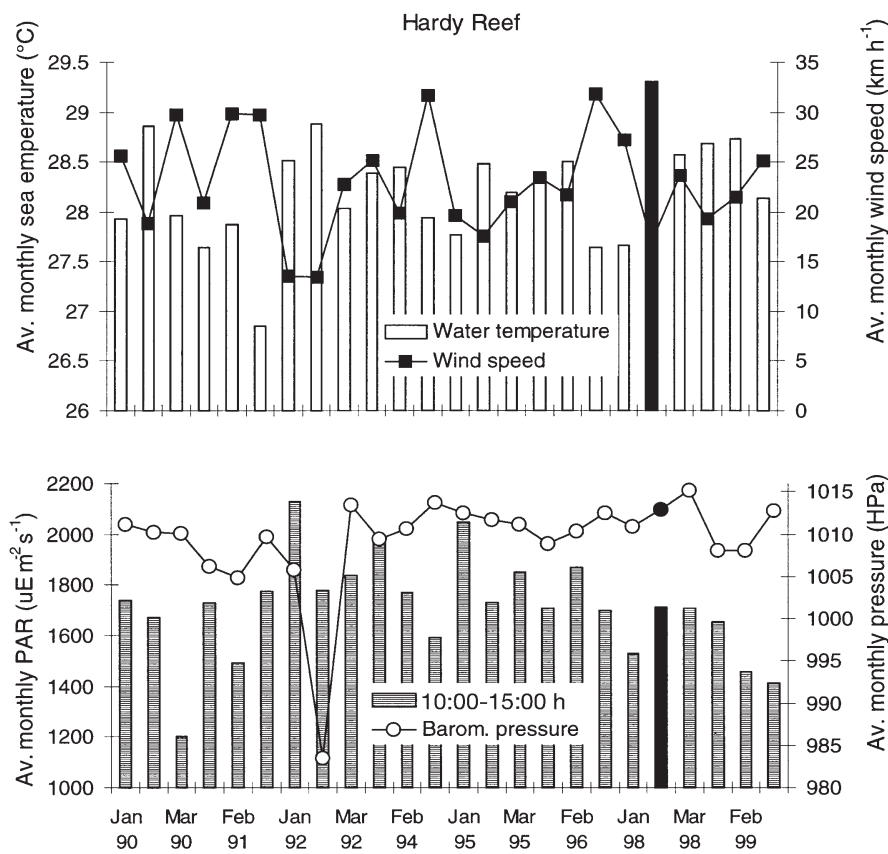

Fig. 3. Average monthly values of sea temperature, wind speed, daytime solar radiation and barometric pressure for Hardy Reef for the warmest 3 months (January to March) between 1990 and 1999. Widespread coral bleaching was evident at this reef in February 1998 (black bars), but at no other time during this 10 yr period. Data for 1993 and 1997 omitted because of large gaps in the data

\section{RESULTS}

An analysis of 10 to $12 \mathrm{yr}$ of meteorological variables at Myrmidon and Hardy Reefs showed that SST associates more strongly with the 1998 coral bleaching event than wind speed, PAR or barometric pressure. At Myrmidon Reef, the monthly mean SST during the height of the bleaching in February 1998 was $29.8^{\circ} \mathrm{C}, 0.3^{\circ} \mathrm{C}$ warmer than the next warmest month (February 1999: Fig. 2). Similarly, at Hardy Reef the average monthly temperature in February 1998 was $0.4^{\circ} \mathrm{C}$ warmer than the next warmest month (February 1992: Fig. 3). No bleaching was recorded at either of these reefs in 1992 or 1999 (Berkelmans \& Oliver unpubl. data). At both reefs, average monthly wind speed was relatively low during February 1998 (17 to $18 \mathrm{~km} \mathrm{~h}^{-1}$ ), but not as low as in 1992, when the average monthly wind speed was 13 to $14 \mathrm{~km} \mathrm{~h}^{-1}$ (Figs. 2 \& 3). Similarly, barometric pressure was unusually high during the 1998 bleaching period compared to other summers, but no higher than in March 1992 and 1994 when no bleaching occurred. Average monthly PAR (10:00 to 15:00 h) was intermediate during the 1998 bleaching period at both reefs compared with previous years (Figs. $2 \& 3$ ). Temperature is thus clearly the most important determinant of coral bleaching and an appropriate variable for use in modeling bleaching thresholds. Bleaching threshold curves based on thermal criteria can be constructed with high resolution using relatively few years of data. For example, at Kelso Reef, thermal tolerance curves were estimated using data from 4 yr (Fig. 4). Exposure

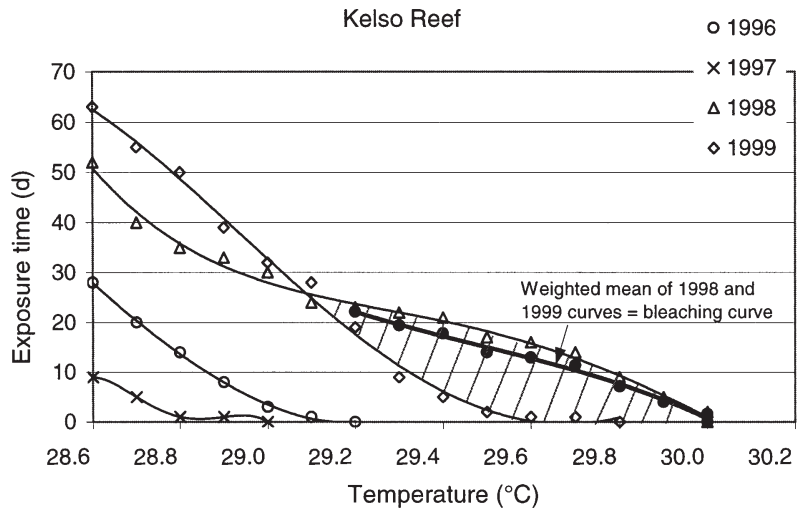

Fig. 4. Example of how the bleaching curve was estimated for Kelso Reef. Cumulative exposure times and temperatures are shown for 4 consecutive years, 1 of which coincided with mild bleaching (1998), for the period when the warmest average daily temperatures are recorded (December to March). Hatched area between the 1998 curve and that for the warmest non-bleaching year (1999) indicates the potential area in time-temperature space in which bleaching could occur. The predicted bleaching curve ( $\bullet-)$ was estimated by weighting the mean on a 5-point scale according to the intensity of bleaching (see Table 1) 


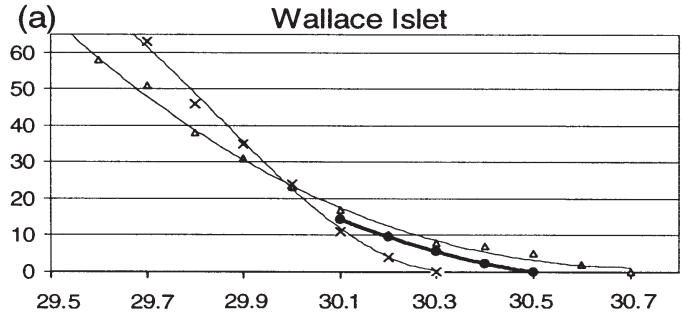

(c)

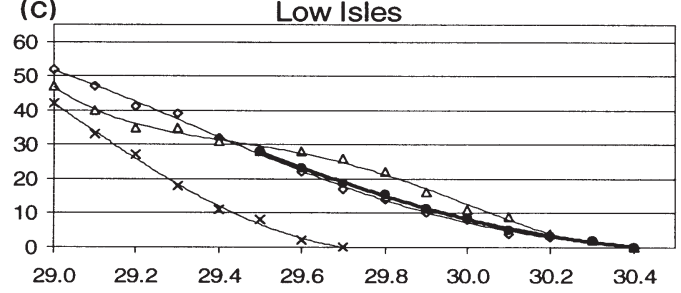

(e)

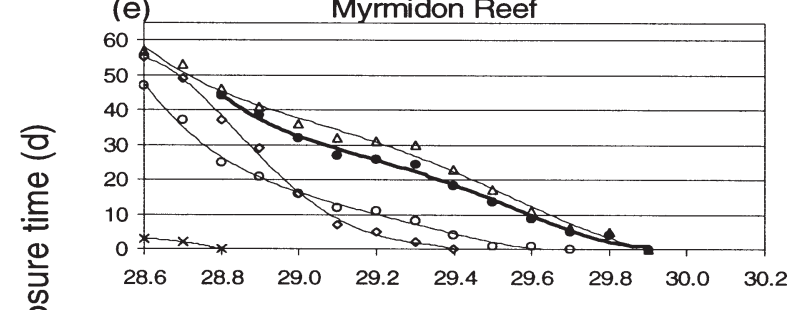

(g)

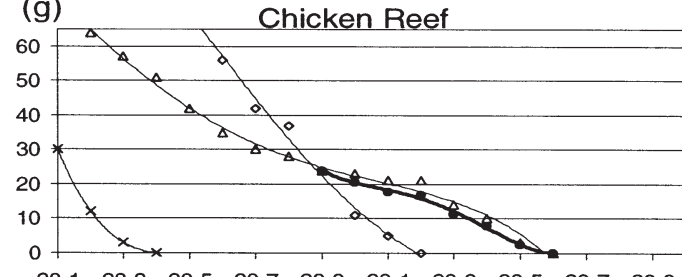

$\begin{array}{llllllllll}28.1 & 28.3 & 28.5 & 28.7 & 28.9 & 29.1 & 29.3 & 29.5 & 29.7 & 29.9\end{array}$

(i)

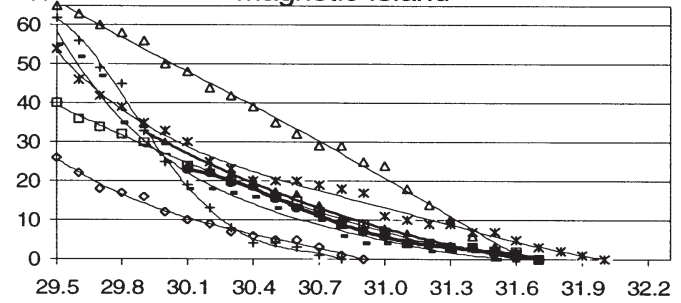

(k)

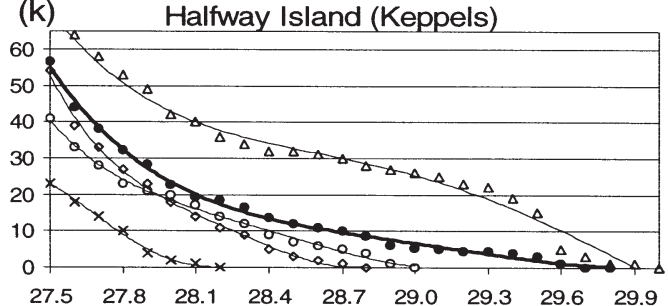

(b)

Daintree coast

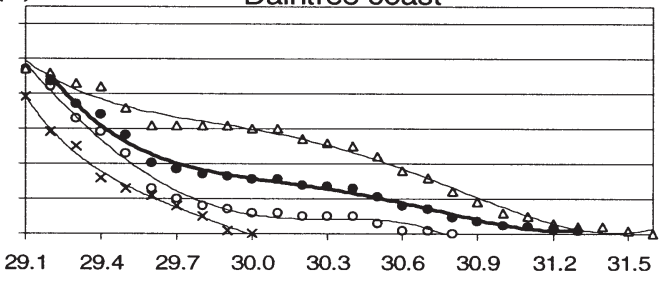

(d)

Norman Reef

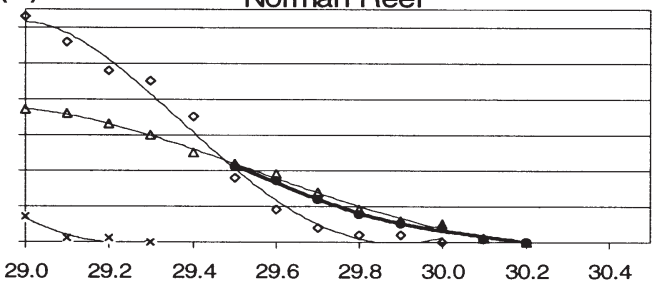

(f)

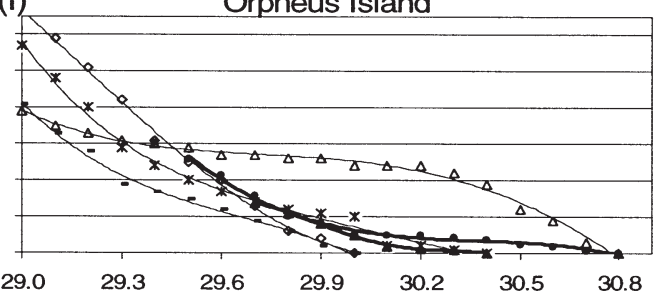

(h)

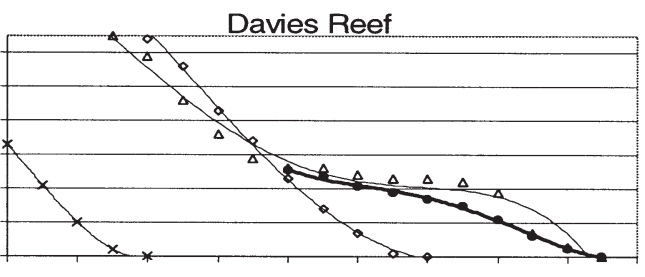

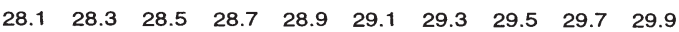

(j)

Daydream Island

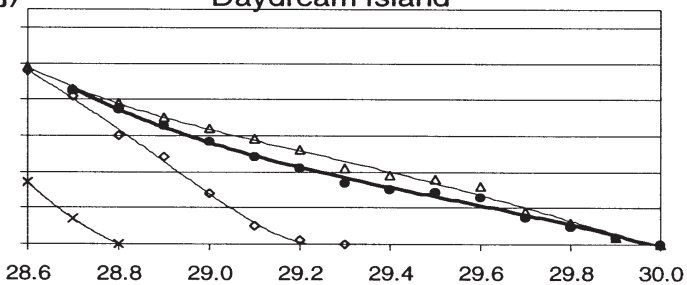

(I)

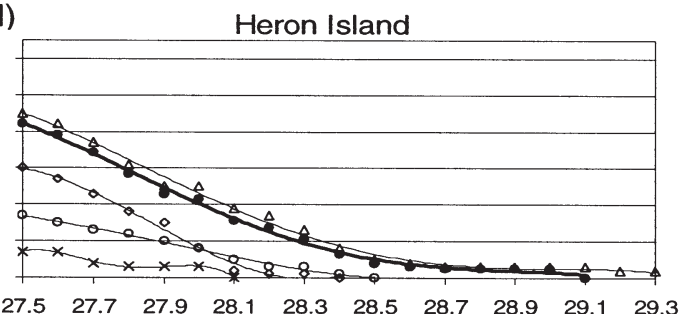

Average daily temperature $\left({ }^{\circ} \mathrm{C}\right)$

Fig. 5. Estimation of bleaching curves for 12 reefs on the Great Barrier Reef. Bleaching curves fitted with polynomial trend lines. $(\diamond)$

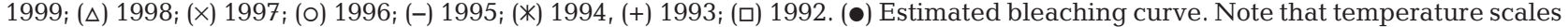
of graphs differ. 1996 and 1997 were cool years at Magnetic Island and Orpheus Island and data were omitted from graphs for clarity. Double bold lines at these 2 sites indicate proximity of bleaching curves estimated with reference to different bleaching years 
times and temperatures in summer represent the righthand side of a normal cumulative distribution for each of 3 non-bleaching years (1996, 1997 and 1999) and 1 bleaching year (1998). During the non-bleaching years, average daily temperatures remained $<29.8^{\circ} \mathrm{C}$ for $1 \mathrm{~d}$ exposure, and $<29.2^{\circ} \mathrm{C}$ for $25 \mathrm{~d}$ exposure (Fig. 4). However, the time-temperature curve for 1998 deviated at $29.1^{\circ} \mathrm{C}$ and had a longer tail, with a maximum temperature of $30.0^{\circ} \mathrm{C}$ experienced for $2 \mathrm{~d}$. Since Kelso Reef suffered mild bleaching in 1998 (Score 4 on a 5-point scale: Table 1), the suggested threshold line is closer to the 1998 curve than the 1999 curve (Fig. 4). The suggested bleaching threshold curves for 12 other reefs were derived in the same way and are shown in Fig. 5. At Orpheus (Fig. 5f) and Magnetic (Fig. 5i) Islands, longer-term temperature records were available ( 6 and 8 summers respectively), and included a number of bleaching events (2 at Orpheus and 3 at Magnetic). For these locations, threshold curves could be estimated with higher precision. For other reefs, like Halfway Island in the southern GBR, the threshold curve is less precise because the time-temperature curve for 1998 deviated greatly from, and did not cross over, the warmest non-bleaching year (Fig. 5k).

The predicted bleaching threshold curves showed considerable variation in shape and offsets over scales of $10 \mathrm{~s}$ to $100 \mathrm{~s}$ of $\mathrm{km}$. For predictive (and locationspecific) purposes, these curves can be modeled using cubic polynomial equations (Figs. $5 \& 6$ ). The shapes of the curves were more variable for inshore reefs than for mid-shelf and outer-shelf reefs (Fig. 6). Bleaching curves also showed considerable separation even for relatively close reefs. For example, the slope (linear component) and the offset for Magnetic Island on the inshore GBR, were substantially different from those of Orpheus Island less than $75 \mathrm{~km}$ to the north.

Distinct spatial trends in the bleaching curves were revealed when the slopes and intercepts of individual bleaching curves were regressed against latitude. Linear model intercepts (temperature axis) showed a significant curvilinear trend with latitude (Fig. 7a), with a plateau towards low latitudes and a sharp decline towards higher latitudes (model fit $\mathrm{r}^{2}=0.44$; regression ANOVA of latitude [transformed by its quadratic function: Fig. 7a] $\left.F=29.54, \mathrm{df}_{1,11}, \mathrm{p}<0.01\right)$. In contrast, model slopes showed no significant trend with latitude (regression ANOVA $F=0.54, \mathrm{df}_{1,11}, \mathrm{p}=0.477$; Fig. $7 \mathrm{~b}$ ). The regression slopes and offsets for the Daintree coast and Magnetic Island were clear outliers in these graphs, a symptom of their geography (see 'Discussion'). When they were excluded from the above analyses the model fit for the curve intercepts on latitude increased to $\mathrm{r}^{2}=$ 0.85 and became more significant. However, the trend for curve slopes with latitude remained non-significant and the model fit did not improve.
The relationship between exposure temperature above a critical level $\left(T_{\mathrm{t}}\right)$ and accumulated heat stress, expressed as 'degree-days', was approximated by a negative quadratic function (Fig. 8). These curves represent lines of equal stress on corals at increasing temperatures above a threshold temperature. Their shape is a function of the rate at which the area under the bleaching threshold curve accumulates at increasing temperatures. The parabolic shape of the curves implies that the number of degree-days required for any one location to commence bleaching is highest at median levels above the threshold temperature and declines on either side of the median. Furthermore, the

(a) Inshore Reefs

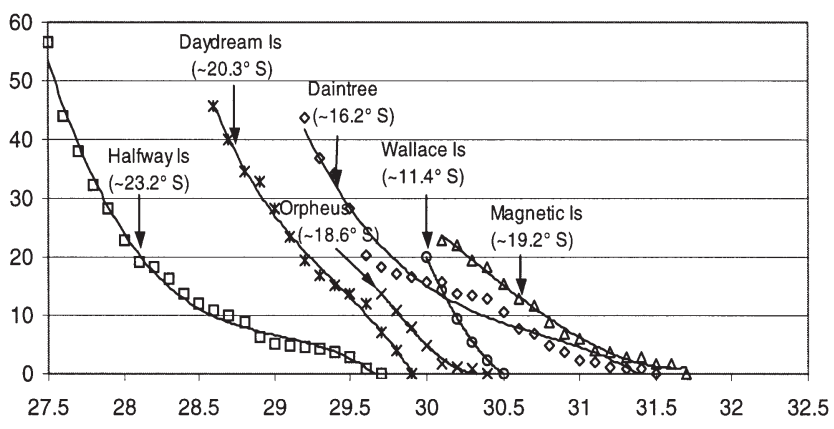

(b) Mid-shelf Reefs

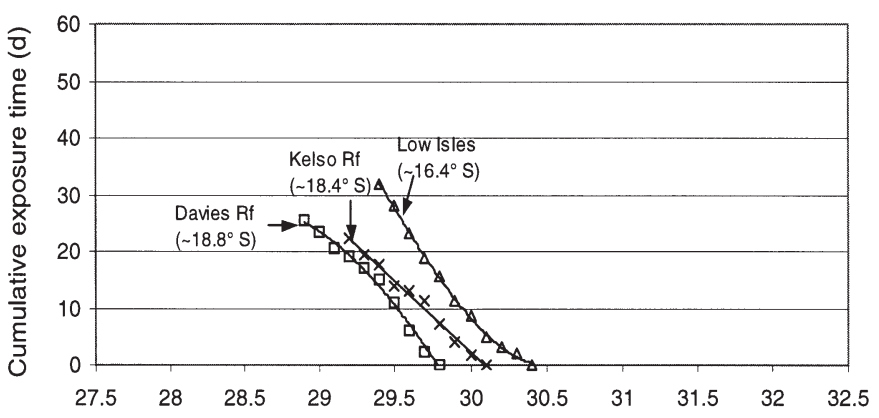

(c) Outer-shelf Reefs

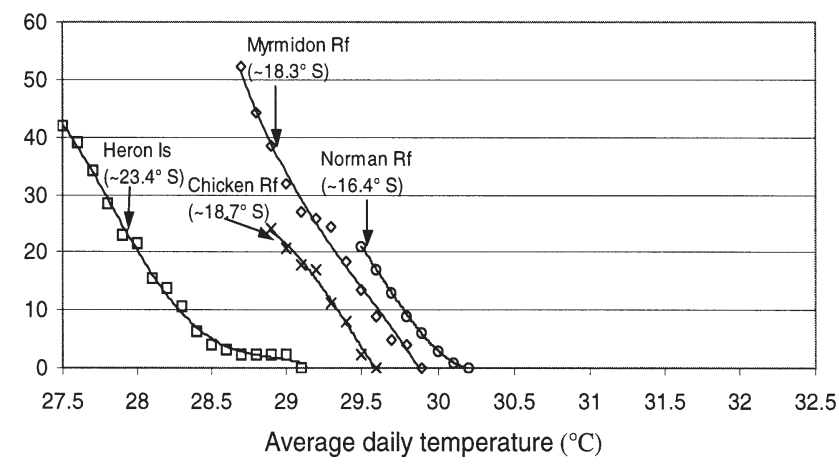

Fig. 6. Spatial comparison of predicted bleaching curves for inshore, mid-shelf and outer-shelf reefs 

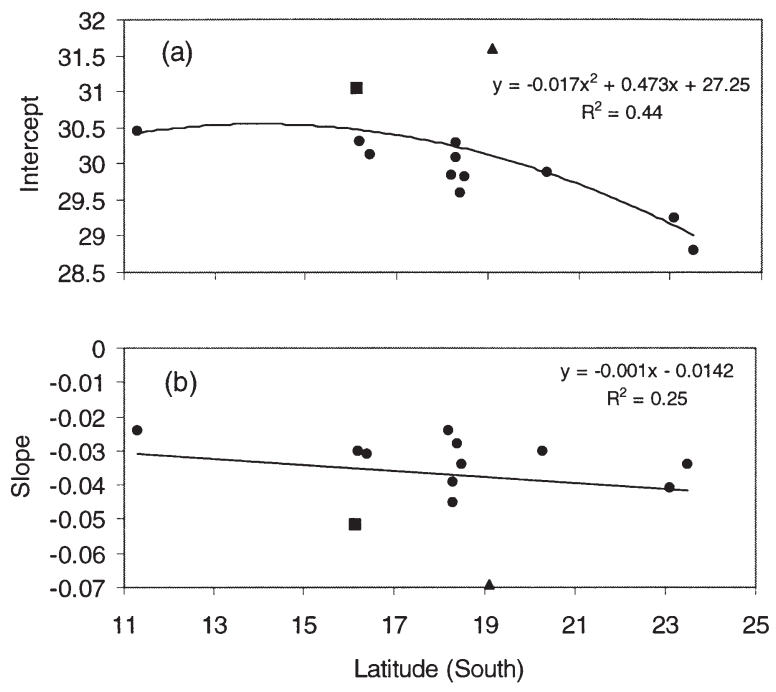

Fig. 7. Latitudinal trend in (a) offsets and (b) slopes of predicted bleaching curves modeled by linear regression. Magnetic Island ( $\mathbf{\Lambda})$ and the Daintree coast ( $\square$ ) are outliers, but have been included in the analysis

curve shape implies that on the left side of the curve time is the dominant integrating factor, while on the right side of the curve temperature above threshold is the dominant integrating factor.

\section{DISCUSSION}

Sea temperature is strongly associated with coral bleaching and its wide availability through cheap data loggers and satellites makes this variable an extremely useful and widely applicable predictor of coral bleaching. Although calm wind conditions and high solar radiation may be important co-occurring factors during coral bleaching (Dennis \& Wicklund 1993, Drollet et al. 1994), the results presented here suggest that these variables by themselves do not correlate with widespread coral bleaching, and their effect on bleaching may only become relevant at high temperatures (see Jokiel \& Coles 1990). In this study, this is demonstrated by high light intensities in the absence of high water temperatures at Hardy Reef (January 1992) and Myrmidon Reef (March 1993) without causing widespread bleaching (Figs. 2 \& 3). Light levels during these months approached the highest theoretical surface light intensities for these locations (Kirk 1983). Fitt et al. (2001) argue that the concept of a 'bleaching threshold temperature' is not meaningful to either corals or humans because the pigment state in corals is naturally variable and can result from many combinations of temperature, light and exposure time. Thus, any reduction in pigment cannot be attributed to any one environmental parameter (such as temperature). However, while high light intensities (at various wavelengths, including PAR, UV-A and UV-B) may confound the interpretation of the bleaching state of corals in the field (especially over small spatial scales $(<1$ to 100 s of $\mathrm{m})$, the evidence remains that elevated temperature is the primary stress factor in widespread 'natural' bleaching events. While light levels may alter the final bleaching state of corals, its effects are secondary (Jones et al. 1998). The physiological mechanism proposed by Jones et al. (1998) to explain the secondary effect of light in bleaching is that temperature damages the biochemical pathway leading to carbon fixation (via the Calvin-Benson cycle) in the zooxanthellae. The blocking of the photochemical pathway in turn results in an overwhelming of Photosystem II with light and the production of reactive oxygen species (Jones et al. 1998, Hoegh-Guldberg 1999). However, because light levels are almost always high at the time of bleaching events (solar radiation drives sea temperature increases), over large spatial scales (1 to $100 \mathrm{~s}$ of $\mathrm{km}$ ), the effect of light intensity in causing variable bleaching responses is effectively
Fig. 8. Predicted bleaching curves recalculated as accumulated heat stress (degree-days) indicating the relationship between 'degree-days' and temperature above average daily thresholds $\left({ }^{\circ} \mathrm{C}\right)$. Resulting curves represent lines of equal thermal stress at various combinations of exposure time and temperature

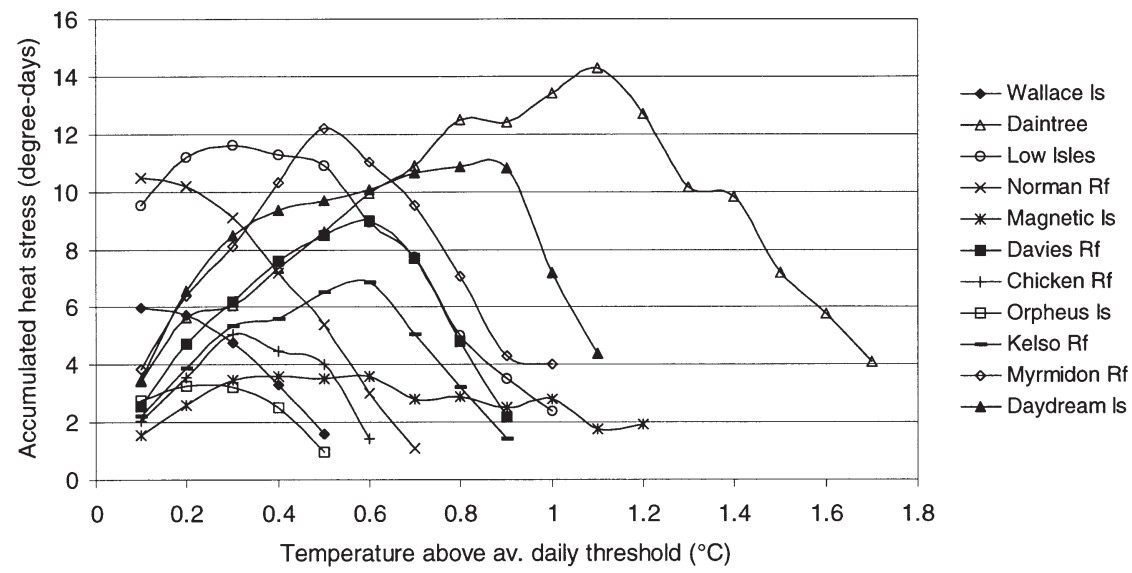


nullified. Thus, at appropriate scales, temperature is a useful and appropriate variable for modeling bleaching thresholds.

The predicted bleaching curves presented here define for the first time the relationship between stress temperature and exposure time for a range of reefs on the GBR. Despite inherent inaccuracies due to the limited number of years of in situ temperature data available, these curves are nevertheless defined within relatively narrow limits and can be more precisely defined as more temperature and bleaching data become available. Although these curves are expressed in terms of thermal criteria, they do in fact incorporate a light component because they are based on in situ bleaching observations, as discussed above. Variation in ambient light regimes and other physicochemical factors at the time of bleaching between sites and between years may also influence the precise position of the curve. Nevertheless, the temporal consistency of these curves at locations that have experienced multiple bleaching events is encouraging and consistent with the notion that temperature is an adequate predictor of bleaching at the scale of reefs and above. At Magnetic Island for example, the time-temperature curves for the bleaching years of 1992, 1994 and 1998 were all higher than the warmest non-bleaching year in 1995. Similarly at Orpheus Island, the bleaching years of 1994 and 1998 were consistently warmer than the warmest non-bleaching year in 1999. The predicted bleaching curves at Magnetic and Orpheus Islands, also showed close agreement with one another regardless of the bleaching year used in the calculation. At Magnetic Island for example, the predicted bleaching curve estimated from temperatures in 1995 (when no bleaching occurred) and 1994 (when mild bleaching occurred) is very similar to the calculated exposure times and temperatures estimated from temperatures in 1995 and 1998 (when very heavy bleaching occurred, Fig. 5i). At Orpheus Island, the bleaching curves estimated from weighted 1994/1999 and 1998/1999 data deviate only at higher exposure temperatures (Fig. 5f). Winter et al. (1998) found similar consistency in the exposure times and temperatures during 4 severe coral bleaching events in Puerto Rico using in situ SST data spanning $30 \mathrm{yr}$. The temporal consistency of the bleaching response of coral communities also indicates that no discernible thermal adaptation response (at least in terms of bleaching) has taken place over this time period.

In contrast, the results from the present study suggest that substantial thermal adaptation may have occurred over a number of spatial scales. This is evidenced by the spatial variation in the bleaching curves of reefs spanning $\sim 1600 \mathrm{~km}$ and $>12^{\circ}$ latitude. This variation in thermal sensitivity mirrors the latitudinal gradient of mid- and outer-shelf reefs, but for inshore reefs the situation is more complex. The position of the bleaching curves for the inshore reefs of Magnetic Island (central GBR) and the Daintree coast fringing reefs (northern GBR) are higher than would be predicted by latitude alone (Fig. 6). Local-scale oceanographic features (enclosed embayments, shallow coastal waters) have resulted in warmer and more variable SST regimes on some inshore fringing reefs compared with offshore reefs and between neighbouring coastal waters. The lack of consistency in thermal regimes with latitude at inshore locations has also resulted in more variable shapes in the bleaching curves for inshore reefs compared with mid- and outershelf reefs. The former are best modeled as polynomials which feature variable regression slopes, whereas curves for mid- and outer-shelf reefs are well modeled by linear regression featuring relatively consistent regression slopes.

Spatial differences in bleaching curves across the GBR shelf are consistent with shelf position at the 3 latitudes investigated $\left(\sim 16,18\right.$ and $\left.23^{\circ} \mathrm{S}\right)$ with 'warmer' curves inshore and 'cooler' curves offshore. The most striking difference occurs in the central GBR, where there is no overlap of exposure temperatures and times between Magnetic Island and either Kelso Reef or Myrmidon Reef (Fig. 6). These cross-shelf trends reflect the trend to deeper water and more stable temperatures near the Coral Sea (Wolanski 1994).

Aside from gaining an understanding of spatial variation in upper thermal limits and thermal sensitivity of populations, the predicted bleaching curves presented here also have application in providing near-real-time warning of coral bleaching. Used in conjunction with automatic weather stations or temperature buoys, the predicted bleaching curves can be incorporated into expert-system computer programs to generate automated warnings of conditions likely to be conducive to bleaching (e.g. Hendee et al. 1998). Such systems complement broad-scale early warning systems such as the satellite-based 'hotspot' system (e.g. Strong et al. 1997), which is spatially comprehensive but lacks fine temporal and spatial resolution. In situ monitoring buoys and weather stations also provide more accurate SSTs at local-scales.

The geographic variation in bleaching curves implies that there may also be patterns in the vulnerability of reefs to climate change. Assessing these patterns of risk is of particular interest to reef-based industries, especially tourism, where investment and growth require long-term planning. The predicted bleaching curves derived in this study represent sub-lethal stress limits of thermally sensitive corals. Among the most sensitive corals are the Acropora species (Oliver 1985, Baird \& Marshall 1998, Marshall \& Baird 2000), which 
also make up by far the highest coral cover and 3-dimensional complexity of Indo-Pacific reefs (e.g. Wallace 2000). On the GBR, tabulate and corymbose Acropora sp. dominated coral cover in 14 of 15 groups of reefs in 1998/1999, covering inshore, mid-shelf and outer-shelf reefs between Cooktown and the bottom of the GBR (present Fig. 1, Sweatman et al. 2000). The bleaching curves thus reflect the bleaching thresholds of the most important living structural element of reefs. In conjunction with regional-scale climate models, these threshold curves can be used to assess how often threshold temperatures may be exceeded in various climate-change scenarios (Charles et al. 1999, HoeghGuldberg 1999).

Accumulated heat stress has been represented by a single number (e.g. 'degree-heating-weeks'), whereby exposure time and temperature are integrated by adding cumulative time above a given temperature (e.g. Gleeson \& Strong 1995). The present study cautions against this approach. Implicit in such a bleaching index is the assumption that there is a linear relationship between exposure time and temperature, i.e. $x$ weeks at $y^{\circ} \mathrm{C}$ above threshold temperature has the same effect as $y$ weeks at $x^{\circ} \mathrm{C}$ above threshold temperature. The results shown here indicate that this relationship is highly non-linear and that a single 'degree-day' bleaching threshold value could indicate a broad range of accumulated heat stress (Fig. 7). At Myrmidon Reef for example, $4 \mathrm{~d}$ at $3^{\circ} \mathrm{C}$ (12 degreedays) above the minimum bleaching threshold would represent a far greater stress impact than $24 \mathrm{~d}$ at $0.5^{\circ} \mathrm{C}$ above threshold (also 12 degree-days; Fig. 8). This result concurs with the conclusion of Winter et al. (1998) that no single temperature variable or index of cumulative heat stress adequately reflects observed temporal bleaching patterns. However, the dual-factor bleaching curves presented here provide a greatly improved representation of thermal triggers likely to cause bleaching stress in corals.

Acknowledgements. Facilities and funding for this study were provided by the Great Barrier Reef Marine Park Authority, the Australian Institute of Marine Science, and the Cooperative Research Centre for the Great Barrier Reef World Heritage Area. I gratefully acknowledge the assistance of the following people and organizations involved in the temperature monitoring program on the GBR: Ken Anthony, Steve Neale, Andrew Chin, Queensland Parks and Wildlife Service, Australian Institute of Marine Science, Ports Corporation of Queensland, Lizard Island Research Station, Quicksilver Connections, Great Adventures, Sunlover Cruises, Pure Pleasure Cruises, Undersea Explorer, Mike Ball Dive Expeditions, Sea Research, Order of Underwater Coral Heroes and Australian Marine Conservation Society, Bundaberg Branch. I am also indebted to Terry Done, Ken Anthony, Janice Lough, Steve Delean and 7 journal reviewers for helpful discussion and comments on earlier drafts of this paper.

\section{LITERATURE CITED}

Achituv Y, Dubinsky Z (1990) Evolution and zoogeography of coral reefs. Coral reefs. In: Dubinsky Z (ed) Ecosystems of the world, Vol. 25 Elsevier, Amsterdam, p 1-9

Baird AH, Marshall PA (1998) Mass bleaching of corals on the Great Barrier Reef. Coral Reefs 17:376

Berkelmans R, Oliver JK (1999) Large scale bleaching of corals on the Great Barrier Reef. Coral Reefs 18:55-60

Berkelmans R, Willis BL (1999) Seasonal and local spatial patterns in the upper thermal limits of corals on the inshore central Great Barrier Reef. Coral Reefs 18:219-228

Brown BE (1997) Coral bleaching: causes and consequences. Coral Reefs 16:S129-S138

Charles SP, Bates BC, Whetton PH, Hughes JP (1999) Validation of downscaling models for changed climatic conditions: case study of southwestern Australia. Clim Res 12: $1-14$

Coles SL, Jokiel PL, Lewis CR (1976) Thermal tolerance in tropical versus subtropical Pacific reef corals. Pac Sci 30: 159-166

Dennis GD, Wicklund RI (1993) The relationship between environmental factors and coral bleaching at Lee Stocking Island, Bahamas in 1990. In: Ginsburg RN (compiler) Proc Colloq on Global Aspects of Coral Reefs: health, hazards and history, 1993. Rosentiel School of Marine and Atmospheric Science, University of Miami, p 167-173

Drollet JH, Faucon M, Maritorena S, Martin PMV (1994) A survey of environmental physico-chemical parameters during a minor coral mass bleaching event in Tahiti in 1993. Aust J Mar Freshw Res 45:1149-1156

Fitt WK, Brown BE, Warner ME, Dunne RP (2001) Coral bleaching: interpretation of thermal tolerance limits and thermal thresholds in tropical corals. Coral Reefs

Gleeson MW, Strong AE (1995) Applying MCSST to coral reef bleaching. Adv Space Res 16:151-154

Glynn PW (1993) Coral reef bleaching: ecological perspectives. Coral Reefs 12:1-17

Glynn PW, Cortes J, Guzman HM, Richmond RH (1989) El Niño (1982-83) associated coral mortality and relationship to sea surface temperature deviations in the tropical eastern Pacific. Proc 6th Int Coral Reef Symp 3:237-243

Hendee JC, Mueller E, Humphrey C, Moore T (1998) A data driven expert system for producing coral bleaching alerts. In: Pepper DW, Brebbia CA, Zannetti P (eds) Proc 7th Int Conf on Development and Application of Computer Techniques to Environmental Studies. Computational Mechanics Publications/WIT Press, Southampton, p 139-147

Hoegh-Guldberg O (1999) Climate change, coral bleaching and the future of the world's coral reefs. Mar Freshw Res 50:839-866

Jokiel PL, Coles SL (1990) Response of Hawaiian and other Indo-Pacific reef corals to elevated temperatures. Coral Reefs 8:155-162

Jones RJ, Berkelmans R, Oliver JK (1997) Recurrent bleaching of corals at Magnetic Island (Australia) relative to air and seawater temperature. Mar Ecol Prog Ser 158:289-292

Kirk JTO (1983) Light and photosynthesis in aquatic ecosystems. Cambridge University Press, Cambridge

Kleypas JA, McManus JW, Meñez LAB (1999) Environmental limits to coral reef development: where do we draw the line? Am Zool 39:146-159

Lough JM (2001) Climate variability and change on the Great Barrier Reef. In: Wolanski E (ed) Oceanographic processes of coral reefs: physical and biological links in the Great Barrier Reef. CRC Press, Boca Raton, FL

Marcus J, Thorhaug A (1981) Pacific versus Atlantic re- 
sponses of the subtropical hermatypic coral Porites spp. to temperature and salinity effects. Proc 4 th Int Coral Reef Symp 2:15-20

Marshall PA, Baird AH (2000) Bleaching of corals on the Great Barrier Reef: differential susceptibilities among taxa. Coral Reefs 19:155-163

McField MD (1999) Coral response during and after mass bleaching in Belize. Bull Mar Sci 64:155-172

Oliver J (1985) Recurrent seasonal bleaching and mortality of corals on the Great Barrier Reef. Proc 5th Int Coral Reef Congr 4:201-206

Pittock AB (1999) Coral reefs and environmental change: adaptation to what? Am Zool 39:10-29

Stoddart DR (1969) Ecology and morphology of recent coral reefs. Biol Rev 44:433-498

Editorial responsibility: Otto Kinne (Editor),

Oldendorf/Luhe, Germany
Strong AE, Barrientos CS, Duda C, Sapper J (1997) Improved satellite techniques for monitoring coral reef bleaching. Proc 8th Int Coral Reef Symp 2:1495-1498

Sweatman H, Cheal A, Coleman G, Fitzpatrick B and 7 others (2000) Long-term monitoring of the Great Barrier Reef. Status Report No. 4., Australian Institute of Marine Science, Townsville, Queensland

Wallace CC (1999) Staghorn corals of the world. CSIRO Publishing, Collingwood, Victoria

Winter A, Appeldoorn RS, Bruckner A, Williams EH, Goenaga C (1998) Sea surface temperatures and coral reef bleaching off La Parguera, Puerto Rico (northeastern Caribbean Sea). Coral Reefs 17:377-382

Wolanski E (1994) Physical oceanographic processes of the Great Barrier Reef. CRC Press, Boca Raton, FL

Submitted: August 22, 2000; Accepted: May 8, 2001 Proofs received from author(s): March 3, 2002 